\title{
LONG-TERM APPROACH FOR MORPHODYNAMIC PROCESSES IN TIDAL MARSH-WATERCOURSES
}

\author{
Monika Donner ${ }^{1}$, Erik Pasche ${ }^{1}$ and Edgar Nehlsen ${ }^{1}$
}

\begin{abstract}
Tidal marsh-watercourses form a significant link between marine and fluvial environment. As consequence bidirectional forces due to asymmetric tides and inland runoff deform morphodynamic processes with presence of cohesive and organic sediment. In combination with the high inter-tidal area proportion and additional anthropogenic deformations special requirements for the long-term approach restrict existing methods. This paper exposes significant processes in tidal marsh-watercourses based on a research study. The identified processes were integrated into a specified long-term approach taking these special requirements into account. By using a numerical model the range of uncertainty for different impacts were considered and results in a long-term riverbed evolution.
\end{abstract}

Keywords: Long-term approach, morphodynamic processes, cohesive sediments, marsh-watercourses, storm surge barriers, suspended sediment influx

\section{INTRODUCTION}

Morphodynamic processes in estuaries result from natural processes (tidal forces, floods and sea level variation), interaction with adjacent secondary network of water bodies and anthropogenic changes in developed coastal zones. Interacting tidal tributaries, like tidal marsh-watercourses, are able to retain sediment and water and function as transitional waters between marine and fluvial environment. As a consequence of human activity, the complex natural system of tidal tributaries has been modified to enhance navigation, farming and settlement through flood defence structures, river regulation, land reclaim, and water management, however neglecting the ecosystem functions of estuaries. Today marshlands in Northern Europe are the most anthropogenic reduced ones with remaining 15\% natural marshes (Greenberg et al., 2004). For agricultural use marshlands have been drained, watercourses were diked and storm surge barriers were built up. By additional deformations like the cut-off of natural tidal creeks and river regulation due to navigation, two central consequences appeared: During ebb tide more than $70 \%$ of the riverbed falls dry and high tides run-up further into backwater than in former times. This development causes severe problems for water management affairs as well as negative impacts on water ecology, which underlines the need for a sustainable water management, as postulated by WFD (EC 2006/60) and the Flood Directive (EC 2007/60). Apart from these legal requirements, climate change and the request for an optimum economic use of estuaries, force a rethinking on planning and realisation of protection and compensation measures. Therefore, tidal marsh-watercourses should be taken into account in prospective holistic approaches.

Until today, only a few research studies like Temmerman (2004) examined morphodynamic processes in marsh-waters. So process-knowledge with focus on long-term evolutions is still incomplete and not satisfactory examined. This paper presents results of a research study at a tidal marsh watercourse, from which significant processes were derived. The identified processes were integrated into a specified long-term approach taking the special requirements of tidal marshwatercourses into account. By using a numerical model the range of uncertainty for different scenarios were considered and results in a long-term riverbed evolution assessment.

\section{PROCESSES IN TIDAL MARSH-WATERCOURSES AND THEIR SCALE IN TIME AND SPACE}

Representative for these marsh-watercourses is the mesotidal, oligihaline river Krückau, which is a tidal tributary of the Elbe estuary in Northern Germany (Figure 1). For process identification, a research study in this tidal marsh-watercourse included field-measurements of hydrodynamics, SPM concentrations, sediment mixture and bathymetric evolution. Bathymetric data measured since 2006 with a Multi-Beam Echo-Sounder was amplified by bearing data since 1998 and analysed in order to derive morphological development. These field experiments proof that anthropogenic stresses like the barrier management at the mouth deform the natural morphodynamic processes by temporal stagnation with settling processes, which is followed by a phase of remobilisation (Donner et al., 2009). But also inland runoff, especially flood events, influences morphodynamic processes. Floods increase fast to peak discharges and conduct high SPM concentrations, which remain during the extended flooddecrease. As consequence, the assessment of long-term hydro- and morphodynamic evolutions requires

${ }^{1}$ Institute of River and Coastal Engineering, Hamburg University of Technology, Denickestrasse 22, 21073 Hamburg, Germany 
a consideration of sensitive long-term boundary conditions including tides, inland runoff forces and control structure management strategies.

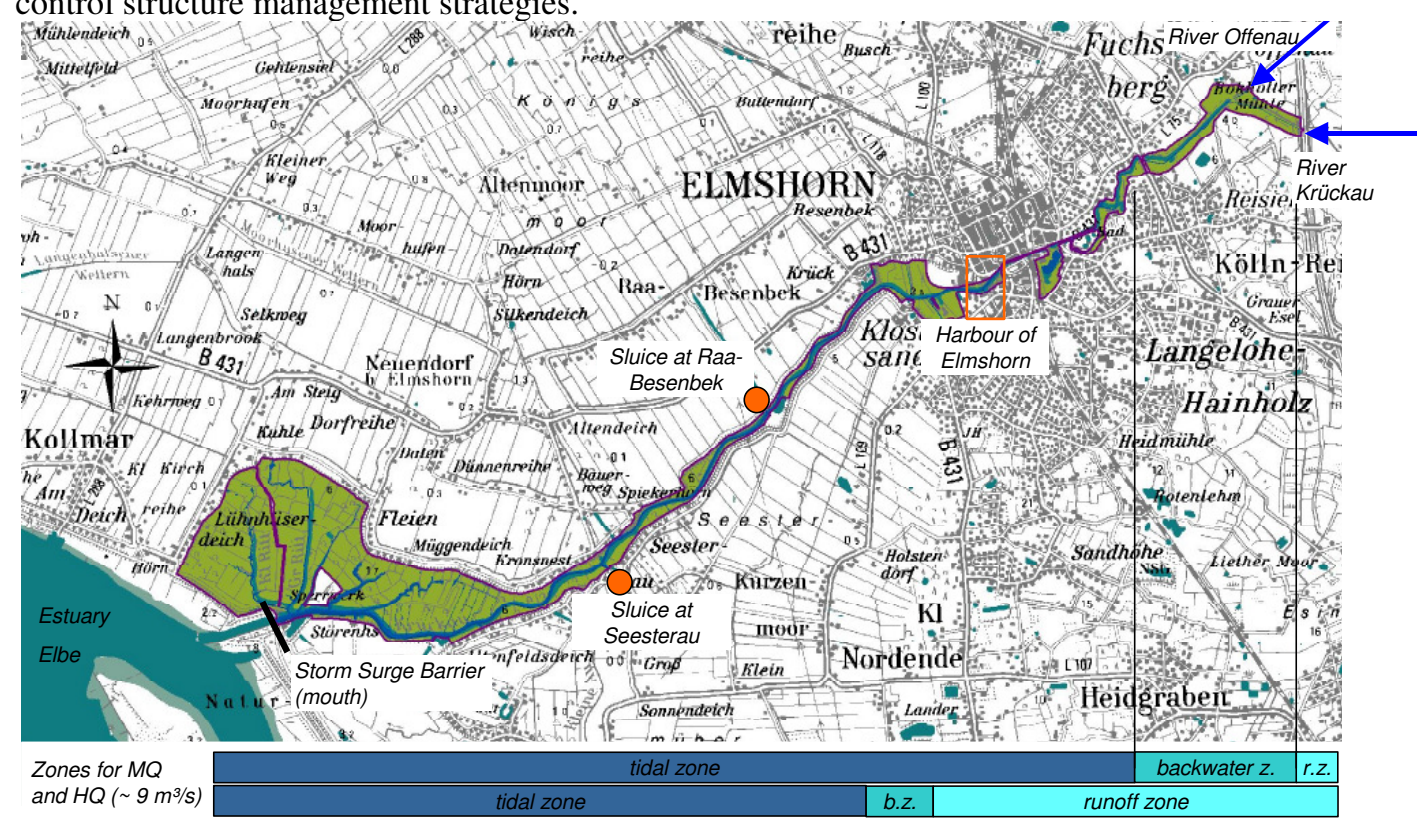

Figure 1: Study Area of the river Krückau and its three process-zones

Hydrodynamic processes represent an internal spatial and temporal dynamic compared to the initiated sediment transport processes, which can result in morphodynamic changes. These interacting processes in time and space require a meso-scale process analysis.

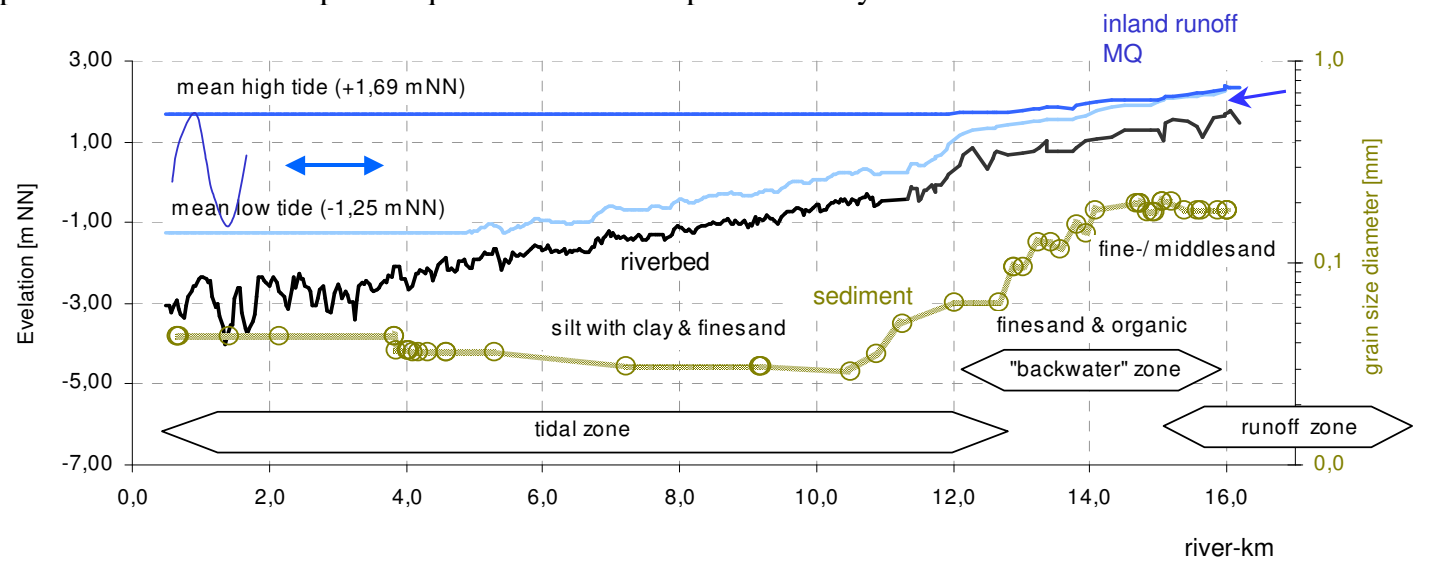

Figure 2: Longitudinal profile of a tidal marsh-watercourse and its three process-zones incl. grain size distribution cross-sectional integrated, here based on the river Krückau

Tidal marsh-watercourses, as the river Krückau, can be divided into three process-zones, a tidal, a backwater and a runoff zone (Figure 2). In the tidal zone bi-directional flow and sediment transport are dominating. In comparison with tidal propagation in coastal zones, the incoming tide already features an asymmetry and deformation due to friction, channel convergence and reflection (Salomon \& Allen, 1983). The tidal curve of the river Krückau is amplified in its asymmetry, due to continuous deepening and constriction of the Elbe estuary. As consequence, flood flow lasts for $5.5 \mathrm{~h}$, while ebb flow takes $7 \mathrm{~h}$. This tidal asymmetry causes a sharp water level rise with a flood flow gradient at slack water and significant weaker ebb flow gradients at slack water. So flood flow gradient, which is a characteristic size for a net suspended sediment transport (Dronkers, 1986), is up to three times higher. Due to low grades of the riverbed and small rates of runoff to tidal inflow (1:10 to 1:150), tides run up fare into the backwater at high tide. During low tide great parts of the riverbed (e.g. 70\% for the river Krückau) are falling dry. Bed load sediment in this tidal zone consists of cohesive, silty particles, which store a high proportion of pore water (clay rate 30 to $70 \%$ ). Small, deep rills drain the saturated riverbanks at ebb tide, re-suspending the cohesive sediment. This process is reflected by high SPM concentrations during low tide $(800-1000 \mathrm{mg} / \mathrm{l})$ and low ones during high tide $(400-200 \mathrm{mg} / \mathrm{l})$. Due to this continuous 
change between aquatic and aerobe environment, processes of consolidation, erosion and deposition occur.

In the backwater zone the flow is no longer bi-directional and mainly forced by inland runoff. Only at high tide the flow is nearly stagnant. Sediment mixture, originated from fluvial sediments, consists of fine-sand and clay. For current at mean flow (MQ $1.3 \mathrm{~m}^{3} / \mathrm{s}$, for the river Krückau) suspended sediment mixture contains high portions of organic matter (up to $30 \%$ ), caused by wash loads and fen grounds. During flood events the portion of fine sand increases.

The runoff zone is completely unaffected by tidal motion. The flow and morphodynamic regime are purely determined by slope driven currents. The landscape changes from Marshes to Moraines (called Geest). Here fine and middle sand dominates although the suspended sediment mixture includes fractions of fine organic peaty flocks $(10-5 \%)$.

\section{LONG-TERM APPROACHES AND THEIR REQUIREMENTS}

\section{State of the art and conclusions for tidal marsh-watercourses}

Any process-based long-term approach for morphodynamic simulations can be subdivided into three components: the long-term boundary and initial conditions, the numerical methods and its acceleration of simulation and the statistical analysis. For all these components methods and techniques in order to predict long-term morphodynamic changes for marine or fluvial environments already exists: A long-term approach for a tidal basin was developed by Zanke et al. (2001) demonstrating opportunities and limitations of morphodynamic modelling in great spatial scales and for long time periods. Different case studies result in a morphological tide according to Latteux (1995) and Steijn (1992), which was used for the prediction of morphodynamic processes over 11 years. Comparable long-term approaches were developed in a process-based model according to Zanke et al. (2004). Recent studies (Junge et al., 2005) developed long-term approaches for estuaries, which are able to include management strategies as well as bi-directional tidal forces. In general approaches for fluvial environment are superposing discharge frequencies with their morphodynamic effect in order to determine the channel-forming discharge (e.g. Doyle et al., 2007). Some modifications of this technique with a time-series analysis of different hydrographs were introduced by Schonlau (2007).

All long-term approaches for estuaries conceive of strong simplifications of inland runoff neglecting discharge variability and flood events. This assumption is not sufficient for tidal marshwatercourses, where inland runoff and tides act in a mutual dominance on hydrodynamics, sediment transport and river morphology. Due to hydraulic structures like storm surge barriers, additional deformations or temporal interruptions of hydro- and morphodynamic processes occur. Thus the approach of morphological tides failed, due to the complexity of impact parameterisation. For transitional waters between fluvial and marine environment with a temporal interrupted dynamic a few methods, but no holistic approach is available.

\section{Special requirements for the long-term approach}

A long-term approach for anthropogenic stressed tidal marsh-watercourses demands certain requirements due to capability of prediction to forecast processes. General requirements are combining integrity (Rubbert, 2007), process scaling (De Vriend, 1993), validity and the capability of prediction (Latteux, 1995). Special requirements educe from the typology and characteristic of tidal marshwatercourses:

Due to asymmetric tides, the high water level and flood flow gradient requires a sufficient time resolution. In addition tides are not the exclusive decisive impact. Flood events, which are lasting over several tides, deform morphodynamic processes in a non-periodic behaviour. So, in the river Krückau, under flood discharges $\left(\mathrm{HQ}_{2} 9.5 \mathrm{~m}^{3} / \mathrm{s}\right)$ the upper boundary of the tidal zone moves about $4 \mathrm{~km}$ downstream and reduce its length with about $25 \%$ compared to low discharges (NQ $0.6 \mathrm{~m}^{3} / \mathrm{s}$ ). The resulting characteristics of morphodynamic processes are varying in time and space depending on intensity and duration of inland runoff and tidal range. As consequence the variability and the combined occurrence of tides and inland runoff must be included into the long-term boundary conditions.

Anthropogenic impacts, which are analysed here exemplarily by storm surge barrier management, induce an interruption and deformation of tidal dynamics and its triggered sediment transport, as shown in Donner et al. (2009). Barrier management amplifies sustainable disturbance of periodic sediment transport processes and bed evolution. Due to the non-linear settling behaviour of cohesive sediments, durations and frequencies of barrier closure play an important role to the resulting bed evolution. Additional the type of barrier management (closure against high or low tide) and the storage level have 
an effect on morphodynamic activities in the backwater zone and at the banks. So an integration of unsteady processes due to barrier management into the long-term approach is necessary.

Cohesive sediments show a non-linear settling behaviour in the water column and a non-linear behaviour at the riverbed over the sediment thickness. The non-linear settling behaviour, which is typically described by an empirical power-law with $S_{\text {dep }} \sim C^{n}$ and $n>1$ (e.g. Krone, 1962), results in limitations of the numerical time step, in order to exclude an overestimation of deposition. Also the depth-resolution of sediment properties, typically realized with a layer-model, also limits the acceleration of simulation. The evolution of sediment properties at the riverbed results in a varying composition of layers and consequently a variant deformation of deposition und erosion properties.

The high inter-tidal area portion, due to subside forelands and an almost slopeless riverbed is one of the key characteristic of tidal marsh-watercourses. Thus frequencies and durations of wetting decide on the existence and intensity of morphodynamic processes (Figure 3). In contrast to the permanent wetted riverbed, only temporal bed evolutions appear especially in higher regions at riverbanks. Due to this characteristic the spatial bed evolution gain an important role. Depositions in higher regions lead to a significant reduction up to a complete prevention of further morphodynamic activity.

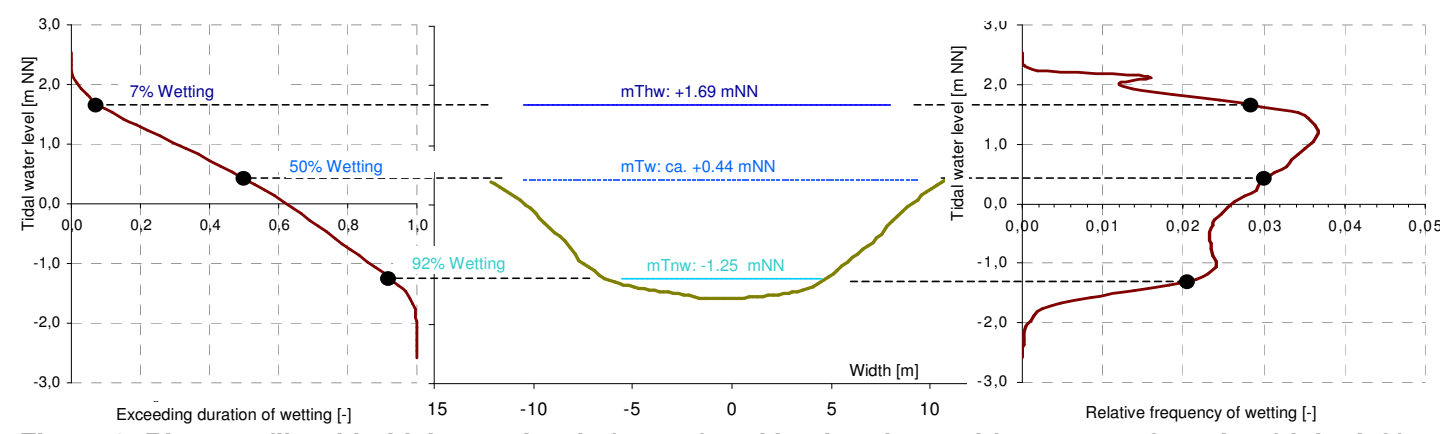

Figure 3: River profile with tidal water levels (centre) and its duration and frequency of wetting (right, left)

\section{METHODOLOGY AND CONCEPT OF THE LONG-TERM APPROACH}

Due to low bed slopes and partly subsided forelands, a one-dimensional implementation of processes is not satisfactory. As de Vriend (1993) already postulated, at least a two-dimensional depthaveraged resolution of sediment transport and hydrodynamics including meso-scale processes for macro-scale questions is necessary in tidal water.

Based on a full spatial and temporal capture of relevant dynamics, like for example the tidal effect on erosion and deposition, long-term evolutions are simplified or parameterised for larger scales. Micro-scale processes, like turbulence and vertical movements (e.g. settling) are aggregated by empirical or time-averaging formulations to the meso-scale. By introducing a morphological factor the processes are transferred from meso- to macro-scale. Different methods based on field measurements, laboratory studies and numerical approaches have been developed for the long-term approach. The variability of boundary conditions like tides and runoff are statistically derived of time series. The nonlinear behaviour of cohesive sediments in the water column (settling velocity) and at the riverbed (soilmodel) is formulated by an empirical approach, based on field measurements, laboratory studies and additional assumptions. In the same way, field measurements on SPM concentrations and their temporal evolution provided a basis for a correlation with hydraulic variables ( $\mathrm{Q}$ and $\mathrm{h}$ ).

The concept of the process-based long-term approach for morphodynamic processes in tidal marsh-watercourses is subdivided into three components:

\section{Long-term boundary conditions}

The long-term boundary conditions describe water and suspend sediment inflow at open boundaries, which are subdivided into discharge $(\mathrm{Q}$ and $\mathrm{C})$ and tidal boundaries $(\mathrm{H}$ and $\mathrm{C})$. The natural discharge range based on measured hydrographs over the last 10-20 a are fragmented into seven classes of discharge based on the month-wise maximum discharge. For each classes a frequency distribution and the range of discharge is determined (Figure 4). A month-wise analysis of the measured hydrographs delivers information about the sequence of low, mean and flood events per hydrological year. Based on this, different scenarios with their ranges of discharge are allocated to significant seasonal occurrence. Long-lasting low discharges arise during summer (Mai and June) with $91 \%$ of the events below MQ, while floods appear during winter (November till March) with up to $65 \%$ of the events exceeding MQ. By scaling time-spans and peak discharges of natural flood waves, synthetic flood waves with a variant duration and flood peak are generated. Additional the maximal 
valid discharge gradient is taken into account. Considering the relative time-scales (de Vriend, 2001) the maximum flood discharge is limited to an $\mathrm{HQ}_{5}$ for a prediction over $20 \mathrm{a}$. The discharge distributions are re-distributed into three so-called basics-scenarios: NQ-MQ-month during summer, NQ-MHQ-month during autumn and winter and MQ-HQ-month during spring. These three basicsscenarios are modified in their duration, based on mean minimal and mean maximal duration curves, integrating the annual frequency variability of discharge. The combination of these basic-scenarios results in synthetic Q-hydrographs, which include typical and statistic floods like $\mathrm{HQ}_{1}, \mathrm{HQ}_{2}$ and $\mathrm{HQ}_{5}$ for each annual type. Apart from the upper inflow boundary, significant tributaries, which increase the discharge of the river Krückau with $30 \%$ were selected (here only one, called Offenau) and included into the long-term approach.

Month-wise frequencies of Q-classes per year at gauging

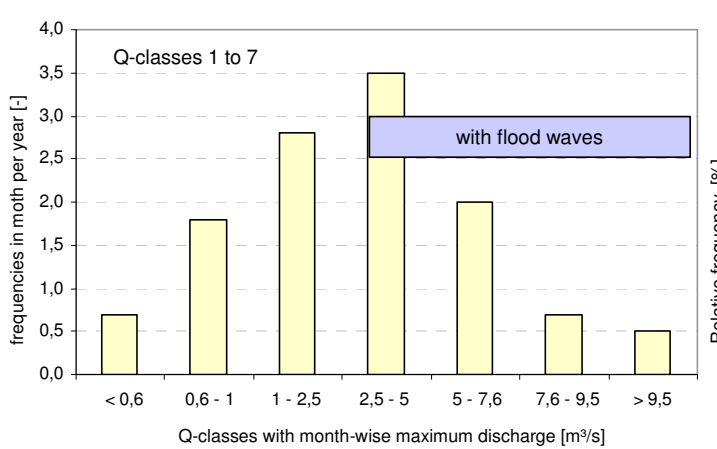

frequency distribution for each Q-class at gauging station A23

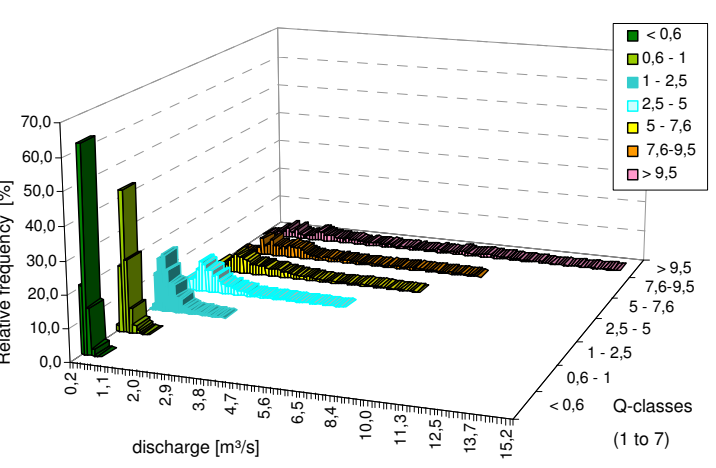

Figure 4: Frequencies of classes of discharge per year (left) and its frequency distributions (right)

For the design of mean neap-spring-tides at the tidal boundary a two methods were applied to measured hydrographs: A partial tidal analysis, which separates the hydrograph in frequencies and amplitudes based on a Fourier transformation and a time-lag method, which uses a time frame of a double neap-spring tide for a time-lag based superposition of tides. For both methods deformed tides due to barrier management were reconstructed by preliminary unaffected tides or by the unaffected hydrographs at the outer gauging station. Only the time-lag method with its final mean neap-springtides delivers a good result concerning tidal asymmetry, which is a decisive criterion for tidal marshwatercourse.

Due to the preliminary filtering of barrier closure, the two typical management strategies (closure against low and high tide) need to be reconstructed. Both strategies not only differ in the stagnation water level, but also in duration and related hydrodynamic processes near the gate (Donner et al., 2009). Selected from the measured hydrographs both strategies were analysed in their duration and seasonal frequencies. The closure against high tide is realized about 7 times per month during winter and 3 times per month during summer. Selected spring tides with its low and high tides are superposed with a simplified surge curve $\Delta \mathrm{H}$ for integration of closure against high tides into the basic neapspring-tide. Depending on the required duration of closure on a water level of $+2.1 \mathrm{~m} \mathrm{NN}$, the increase $\Delta \mathrm{H}$ cover 20,50 and $100 \mathrm{~cm}$ for closure over $1.5,3.0 \mathrm{~h}$ and $4.5 \mathrm{~h}$. The superposition starts and ends on the level of mean tide. For closure against low tide, which is realized about 6 times per year during summer, the stagnant water level is fixed by operation rules on $+1.6 \mathrm{~m} \mathrm{NN}$. The gate is closed during ebb flow and opened during flood flow at this stagnant water level. Due to the impact on sediment transport and hydrodynamics as proved in Donner et al. (2009), also gate operation of closure and opening needs to be included. Thus the unsteady process of gate operation induces different forms of down- and upsurges depending on flow direction and gate operation. These operational processes are included with a fine numerical time resolution over $4 \mathrm{~min}$, while tidal boundary is closed stepwise from outside. During the stagnant period, numerical time steps are also reduced to 5 or 10 min, considering the non-linear settling behaviour of suspended sediments. The reopening of the gate is realized within a 5 min time frame. Due to the seasonal characteristics of barrier management, so-called synthetic summer neap-spring-tides with 1 closure against low tide and 3 closures against high tide $(2.1 \mathrm{~h})$ per month and so-called synthetic winter neap-spring-tides with 7 closures against high tide (1.5 to $4.5 \mathrm{~h}$ ) per month are determined. 


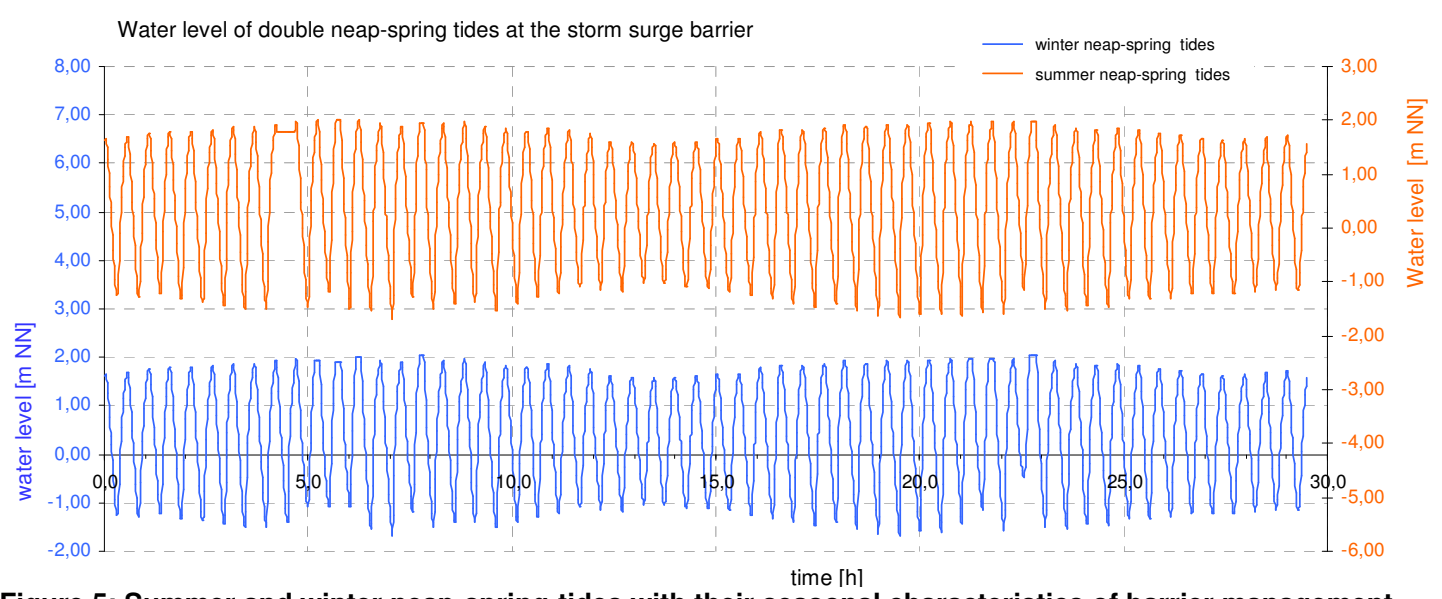

Figure 5: Summer and winter neap-spring-tides with their seasonal characteristics of barrier management

Each open boundary requires a suspended sediment influx, which can be simplified to zero, a constant value or variable depending on one or several variables. Due to field measurements at and near the inflow and the tidal boundaries, which provide SPM concentration for different discharges and tides, a variable approach was applied. A regression analysis of SPM concentrations C and inflow Q at the inflow boundaries results in logarithmic regression functions. Therefore measured SPM concentrations $\mathrm{C}$ were integrated over depth and channel width to cross-sectional averaged size. The initial cross-sectional variation of $\mathrm{C}$ is represented by its 10 and $90 \%$-quantile (Figure 6). Based on these logarithmic functions the sediment influx can be correlated with hydrograph. Maximum delta between the logarithmic function and the cross-sectional averaged concentration varies between +90 to $-63 \%(+150$ to $-200 \mathrm{mg} / \mathrm{l})$ in the river Krückau and between +33 to $-43 \%(+90$ to $-130 \mathrm{mg} / \mathrm{l})$ in the river Offenau. This natural variation will be examined later in different scenarios.
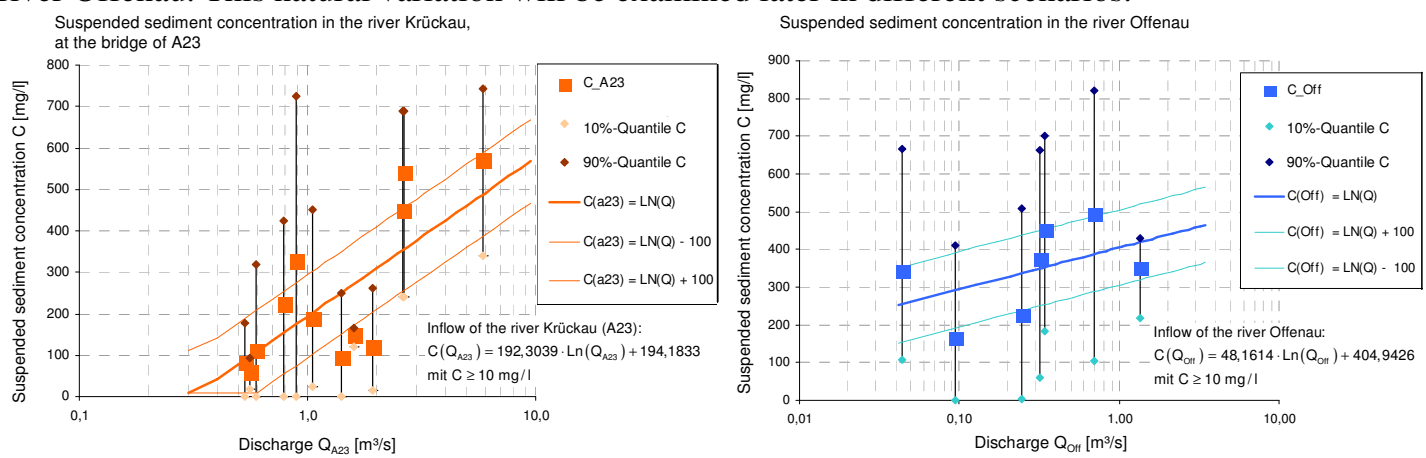

Figure 6: SPM concentration over discharge in the river Krückau (left) and in the river Offenau (right)
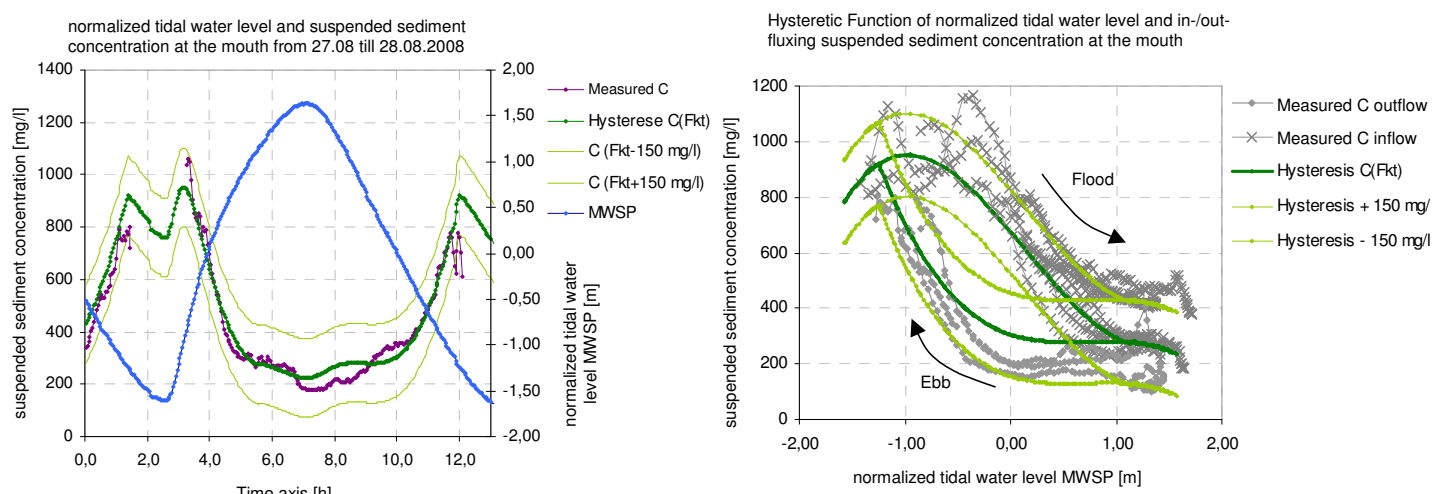

Ebb phase and if MWSP $>1,12$ :

$\mathrm{C}(\mathrm{MWSP})=-86,6724 \cdot \mathrm{MWSP}^{3}+187,3311 \cdot \mathrm{MWSP}^{2}-124,6326 \cdot \mathrm{MWSP}+305,3189$

Flood phase and if MWSP $<-1,25$ :

$\mathrm{C}(\mathrm{MWSP})=120.6283 \cdot \mathrm{MWSP}^{3}-52.1721 \cdot \mathrm{MWSP}^{2}-449.5408 \cdot \mathrm{MWSP}+675.0636$

Figure 7: SPM concentration over normalized tidal water level MWSP at the mouth, hysteretic functions and measured values 
A regression analysis of SPM concentrations C and normalized tidal water level MWSP at the mouth results in hysteretic functions. The normalized tidal water level MWSP represents the subtraction of mean water level (MT1/2w) from tidal water level and varies between -1.6 and $+1.6 \mathrm{~m}$. The hysteretic functions differ between an ebb phase (here simplified, from high to low tide) and flood phase (here simplified, from low to high tide). SPM concentrations increase at first slightly from $280 \mathrm{mg} / \mathrm{l}$ and then faster (MWSP > 0) to a maximum of $900 \mathrm{mg} / \mathrm{l}$ during ebb phase (Figure 7, right). During flood (Figure 7, right) the SPM concentrations decrease rapidly from $950 \mathrm{mg} / \mathrm{l}$ (MWSP $>0$ ) and stabilize near $280 \mathrm{mg} / \mathrm{l}$. All measured SPM concentrations differ less than $\pm 50 \mathrm{mg} / \mathrm{l}$ (tidal averaged delta) from the hysteretic functions. Both hysteretic functions are only applied for SPM influx during flood flow at the open boundary. No boundary values are given during ebb flow and barrier closure.

\section{Multi-layer soil-model}

The initial conditions focus on the spatial sediment distribution at the riverbed and their properties over depth. Therefore a zoning of the bed, a sampling and a laboratory analysis of sediment mixture (grain size distribution and ignition loss) were realized. Empirical approaches are applied to quantify erosion and deposition behaviour based on these grain size distributions and leads to a multi-layer soilmodel for each sediment zone.

The significant sediment properties over depth were parameterised in order to quantify vertical exchange rates. Therefore two different types of soil-layers are differentiated: The soft, recent deposited "suspended layers" (SL), which describes the non-linear behaviour over a small depth (few centimetres), and the underlying, consolidated "bed layers" (BL), which represent an almost linear behaviour over depth. For the long-term approach a maximum of 8 suspended and 8 bed layers are provided for a depth-discretisation over $3 \mathrm{~m}$, with discrete characteristic property (porosity, bulk density, critical shear stress, erodibility). The vertical exchange of sediments is based on the Lagrange method, therefore the top layer properties decide about the intensity of erosion and deposition.

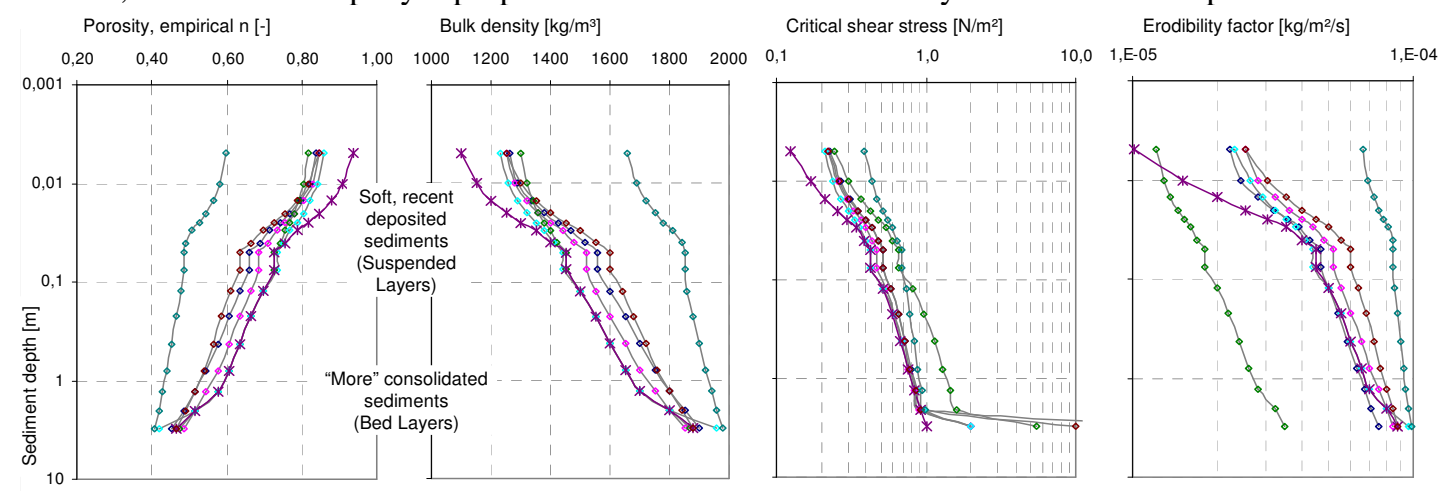

Figure 8: Multi-layer soil model for cohesive sediments and the property behaviour over depth

For the characteristics of cohesive sediments the porosity $\mathrm{n}$ is presumed to be the primary. Secondary properties like bulk density, critical shear stress and erodibility revert to this primary property. Empirical formulas according to Allersma (1988, in van Rijn, 1993) in eq.(1) above and Lane and Koelzer (1953, in van Rijn, 1993) in eq. (1) below were applied based on grain size distributions and provide a range of dry bulk densities for the upper suspended layer (SL) down to the lowest bed layer $(\mathrm{BL})$.

$$
\begin{aligned}
& \rho_{b, d r y}=480 \cdot \alpha+(1300-280 \alpha) \cdot p_{\text {Sand }}^{0.8} \quad \text { with } \alpha=0.0 \text { for } \mathrm{SL} \\
& \rho_{b, d r y}=817 \cdot\left(100 \cdot p_{\text {Sand }}+2\right)^{0.13}, \text { with for } \mathrm{BL}
\end{aligned}
$$

where $\mathrm{p}_{\text {sand }}$ is sand fraction of grain size distribution [-], $\alpha$ coefficient for consolidation between 0.0 and 2.4 and $\rho_{\mathrm{b}, \mathrm{dry}}$ dry bulk density $\left[\mathrm{kg} / \mathrm{m}^{3}\right]$. For the critical shear stress two approaches according to Zanke (1982) were modified and combined in eq. (2), in order to derive a continuous transition between soft, liquid layer (SL) to consolidated layers (BL). 


$$
\begin{aligned}
& \tau_{c, \text { ero }}(z)=(n) \cdot \tau_{c, \text { ero, } \min }+(1-n) \cdot \tau_{c, \text { ero }, \text { max }} \\
& \text { with : } \tau_{c, \text { ero } \min }=0.905^{2} \cdot \rho_{w} \cdot\left(\frac{\rho_{b, w e t}^{2}-\rho_{w}^{2}}{\rho_{b, \text { wet }} \cdot \rho_{w}} \cdot g \cdot v\right)^{2 / 3} \quad \text {, for SL } \\
& \text { with: } \tau_{c, \text { ero } \max }=0.004 \cdot\left(\frac{S_{v}}{n \cdot \rho_{w}}\right)^{1 / 2} \text {, for BL }
\end{aligned}
$$

where $\rho_{\mathrm{b} \text {,wet }}$ is wet bulk density $\left[\mathrm{kg} / \mathrm{m}^{3}\right], \mathrm{n}$ porosity $[-], \mathrm{g}$ gravity $\left[\mathrm{m} / \mathrm{s}^{2}\right], v$ cinematic viscosity of water $\left[\mathrm{m}^{2} / \mathrm{s}\right], \rho_{\mathrm{w}}$ water density $\left[\mathrm{kg} / \mathrm{m}^{3}\right], \mathrm{S}_{\mathrm{v}}$ wing shear resistance 8.8 to $27.6 \mathrm{kN} / \mathrm{m}^{2}$ (Zanke, 1982), between 2 to $7 \mathrm{kN} / \mathrm{m}^{2}$ for a tidal harbour basin and $\tau_{\mathrm{c}, \text { ero }}$ shear stress $\left[\mathrm{N} / \mathrm{m}^{2}\right]$. The critical shear stress based on eq. (2) is varying between 0.21 to $0.68 \mathrm{~N} / \mathrm{m}^{2}$ for suspended layers and 0.4 to $2.0 \mathrm{~N} / \mathrm{m}^{2}$ for bed layers. The erodibility factor is determined by an empirical formula integrating the dry bulk density according to Schweim (2005):

$$
\beta_{\text {ero }}=k^{*} \cdot \rho_{b, d r y} \quad \text { with } \mathrm{k}^{*}=6.23 \cdot 10^{-7}
$$

where $\rho_{\mathrm{b} \text {,wet }}$ is wet bulk density $\left[\mathrm{kg} / \mathrm{m}^{3}\right], \mathrm{k}^{*}$ coefficient $[\mathrm{m} / \mathrm{s}]$ and erodibility factor $\left[\mathrm{kg} / \mathrm{m}^{2} / \mathrm{s}\right]$. The erodibility factor based on eq. (3) is varying between 0.2 to $0.7 \mathrm{~g} / \mathrm{m}^{2} / \mathrm{s}$ in the tidal zone and 0.7 to $0.9 \mathrm{~g} / \mathrm{m}^{2} / \mathrm{s}$ in the runoff-zone. These ranges show good consistencies to a simple quantified erodibility factor of 0.1 to $2.0 \mathrm{~g} / \mathrm{m}^{2} / \mathrm{s}$ based on measured SPM concentration gradients over time.

\section{Physical based process-model and the temporal acceleration}

All hydro- and morphodynamic processes are simulated by the two-dimensional, depth-integrated (except bed evolution) based on a FE method. The numerical method approximates the exact solution function based on Galerkin approach in combination with a Netwon-Raphson method (Schrage et al., 2009). The implicit scheme formulates the time dependency by a modified Crank-Nicholson approach, enables accurate numerical time steps up to 20 minutes and reduces the simulation effort. For each time step hydrodynamics, suspended sediment transport and a reduced bed evolution is solved in a coupled scheme (Figure 9). The solution of hydrodynamics is realized based on 2 d, Reynolds-averaged shallow water equations. The impact of bed roughness is introduced by the Colebrook-White resistance formula, which is optional superposed with additional flow resistance, due to rigid vegetation on the floodplain. In order to quantify turbulence an eddy viscosity approach is applied, which superposes the Prandtl mixing length (Smagorinsky enclosure) with a bed shear stress induced approach. Processes of drying and wetting are included with a special combination of overland and groundwater flow. The $2 \mathrm{~d}-$ advection-diffusion equation solves suspended sediment transport processes. The parameterisation of the diffusion coefficients is based on a modified approach of the turbulent diffusion. Half-empirical approaches quantify the vertical exchange rates between water column and riverbed. For deposition rates the approach according to Krone (1962) and Partheniades (1965) in Dronkers (1988) is applied. Settling velocities are derived for cohesive $(0.025$ to $0.35 \mathrm{~mm} / \mathrm{s}$ for 100 to $1000 \mathrm{mg} / \mathrm{l})$ and organic sediments $(0.175$ to $0.34 \mathrm{~mm} / \mathrm{s}$ for 10 to $900 \mathrm{mg} / \mathrm{l}$ ) based on laboratory studies and are formulated by a power law. For erosion rates the approach according to Partheniades (1965), in Dronkers (1988), which includes the formulated critical shear stress and erodibility factor from above, is used. The bed evolution solves a reduced Exner-equation neglecting bed load transport and by using vertical exchange rates of the $2 \mathrm{~d}$-advection-diffusion equation. Due to mass balance erosion or deposition initiates an evolution of the multi-layer soil model based on the Lagrange method. By using a predictor concept the resulting bed level change is transferred to the variables of hydrodynamics.

The shallow water equations are only time averaged for the meso-scale and use an eddy viscosity approach to describe the turbulent shear stresses. Additionally the predictor concept, an implicit and an uncoupled scheme achieve a slight temporal acceleration. By applying morphological factors according to Latteux (1995, "lengthening"), which accumulates the bed evolution processes for longer periods in one time step by a MF, a sustainable reduction of simulation time is achieved. Therefore hydrodynamics and sediment transport are modelled for one time step, while the bed level and its underlying soil-model change MF-times faster. Additional, the accelerated bed evolution gives a direct feedback to hydrodynamics in the next numerical time step. As one basis for this approach, bed evolution for the accelerated time-scale must be so small, that no significant error for bed evolution, hydro- and morphodynamic processes arise. Bed evolution in the runoff-zone processes on long-lasting and meta-stable equilibrium states, while bed evolution in the tidal-zone shows a periodic behaviour with no or just a slight tidal integrated trend. Both phenomena are taken into account by the MF 
approach: The periodic behaviour of the tidal-zone can be increased in its intensity, without deforming hydrodynamics and suspended sediment transport, as proved later. In the runoff-zone erosion and deposition represent an asymptotic character, which tends to a stabile bed level after disturbance.

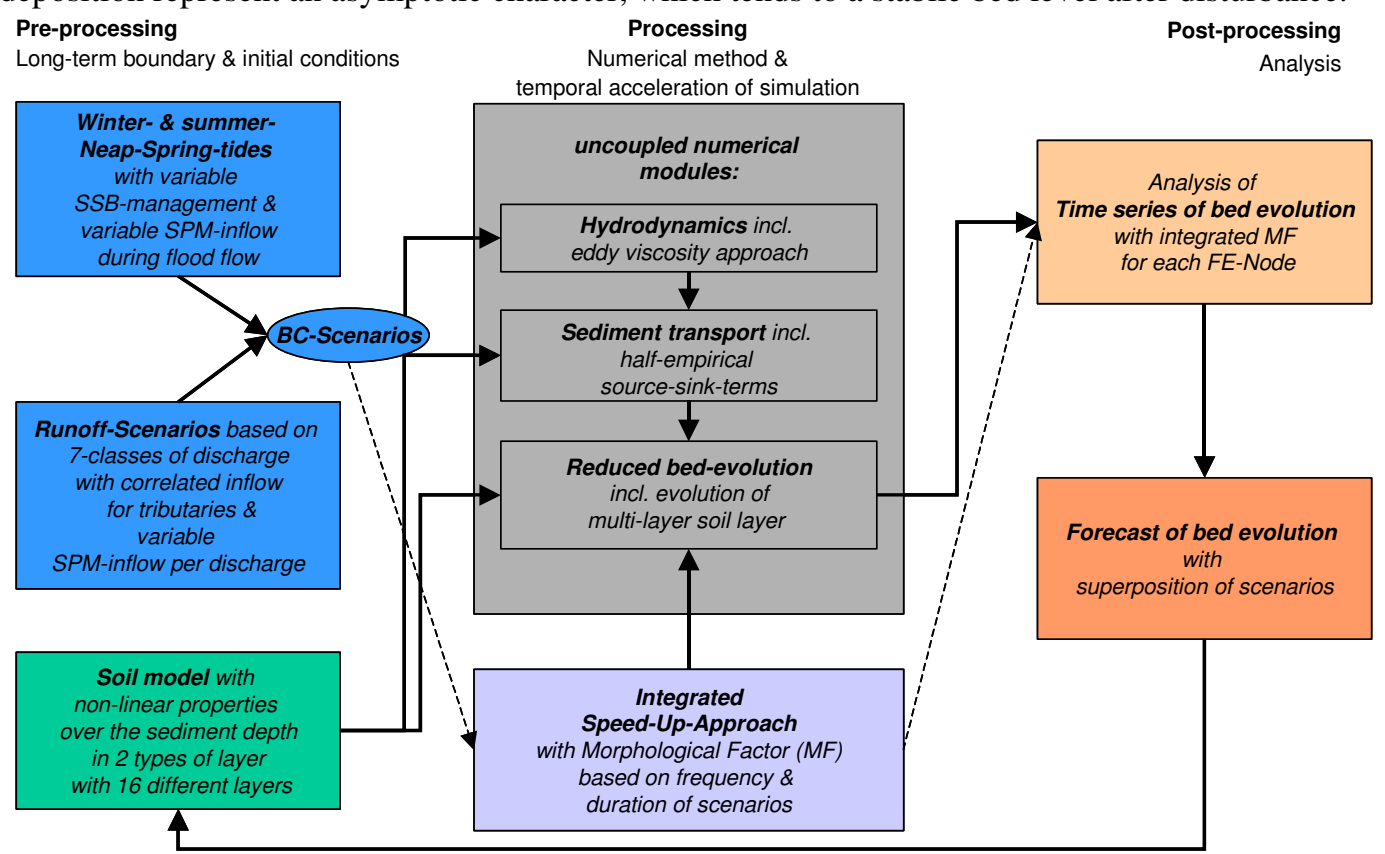

Modelling Software: RMA-KALYPSO (based on RMA10s, RMA-Family), Resource Management Associates. Source: Waterways experiment station (WES) des US Army Corps of engineers (USACE): Further development at TUHH. User Interface in cooperation with BCE: OpenSource >> www.sourceforge.net $>>$ KALYPSO

\section{Figure 9: Concept for long-term approach}

Instead of an extrapolation of bed evolution of one time span up to several spans, the MF-approach takes the non-linear sediment behaviour in the multi-layer soil-model into account. As consequence an exchange rate over MF-times is damped inside a numerical time step with its effect, due to changing properties over depth. During an accelerated time-step a layer-overlapping erosion or deposition can occur, if one layer is completely eroded or filled up. If such a layer-overlapping erosion occurs, the erosion rate for the suspended sediment transport is adopted and averaged over the accelerated timestep. A layer-overlapping deposition has no retroactive impact on the deposition rate of the suspended sediment transport.

Table 1: Synthetic basic scenarios for the long-term boundary conditions and their morphological factors

\begin{tabular}{|l|lll|}
\hline & Tidal boundary & Inflow boundary & $\begin{array}{l}\text { Duration } \\
\text { Frequency/ MF }\end{array}$ \\
\hline $\begin{array}{l}\mathrm{NQ}-\mathrm{MQ} \\
\text { (Summer) }\end{array}$ & $\begin{array}{l}\text { Summer neap-spring-tides } \\
+1 \text { closure against low tide } \\
+3 \text { closure against high tide }\end{array}$ & $\begin{array}{l}\text { NQ-MQ-month, } \\
0.20 \text { to } 1.3 \mathrm{~m}^{3} / \mathrm{s}\end{array}$ & $\begin{array}{l}29.53 \text { days } \\
\mathrm{MF}=6.82 \text { to } 4.96\end{array}$ \\
$\begin{array}{l}\mathrm{MQ}-\mathrm{MHQ} \\
\text { (Winter) }\end{array}$ & $\begin{array}{l}\text { Winter neap-spring-tides } \\
+7 \text { closure against high tide }\end{array}$ & $\begin{array}{l}\mathrm{MQ}-\mathrm{MHQ}-\mathrm{month}, 0.40 \text { to } 5.0 \mathrm{~m} / \mathrm{s} \\
\text { (incl. flood waves) }\end{array}$ & $\begin{array}{l}59.06 \text { days } \\
\mathrm{MF}=1.78 \text { to } 2.37\end{array}$ \\
$\begin{array}{l}\text { MQ-HQ } \\
\text { (Winter) }\end{array}$ & $\begin{array}{l}\text { Winter neap-spring-tides } \\
+7 \text { closure against high tide }\end{array}$ & $\begin{array}{l}\text { MQ-HQ-month, } 1.3 \text { to } 11.5 \mathrm{~m}^{3} / \mathrm{s} \\
\text { (incl. flood waves and statistic } \\
\text { flood events) }\end{array}$ & $\begin{array}{l}59.06 \text { days } \\
\mathrm{MF}=1.01 \text { to } 1.34\end{array}$ \\
\hline
\end{tabular}

The morphological factor results from frequencies of simulated scenarios or their duration inside a representative time span. The developed synthetic basic scenarios consist of typical seasonal ranges of discharge and the related neap-spring tides (Table 1) The alignment of these scenarios over the prediction time span during the ante-validation span is based on the known intensity of hydrological years and during the post-time span, the statistical frequencies of flood events are maintained. Due to the high variability of tides, which is displayed with a neap-spring tide, and its interaction with the inland runoff, the MF has some limits based on hydrodynamic impacts.

\section{Calibration and validation of processes on meso-scale}

For the calibration and validation of hydrodynamic and sediment transport processes on mesoscale, real time series at the open boundaries and short time spans over a few days are simulated. Therefore measured time series for hydrodynamics, like water level and flow velocities, and for 
suspended sediment concentrations in the tidal and backwater zone are compared to simulated time series. In order to quantify the model performance, simulated and measured time series are evaluated by the ARMAE according to van Rijn et al. (2002):

$$
A R M A E=\frac{\left\langle\left|c_{c}-c_{m}\right|-\Delta c_{m}\right\rangle}{\left\langle\left|c_{m}\right|\right\rangle} \quad: \text { Adjusted relative mean absoulte error }
$$

where $\mathrm{c}_{\mathrm{c}}$ is the simulated value, $\mathrm{c}_{\mathrm{m}}$ the measured value, $\Delta \mathrm{c}_{\mathrm{m}}$ the permitted precision and $\langle\ldots\rangle$ temporal averaging. The ARMAE is classified depending on water level, velocities and SPM concentration into a range from excellent to pore.

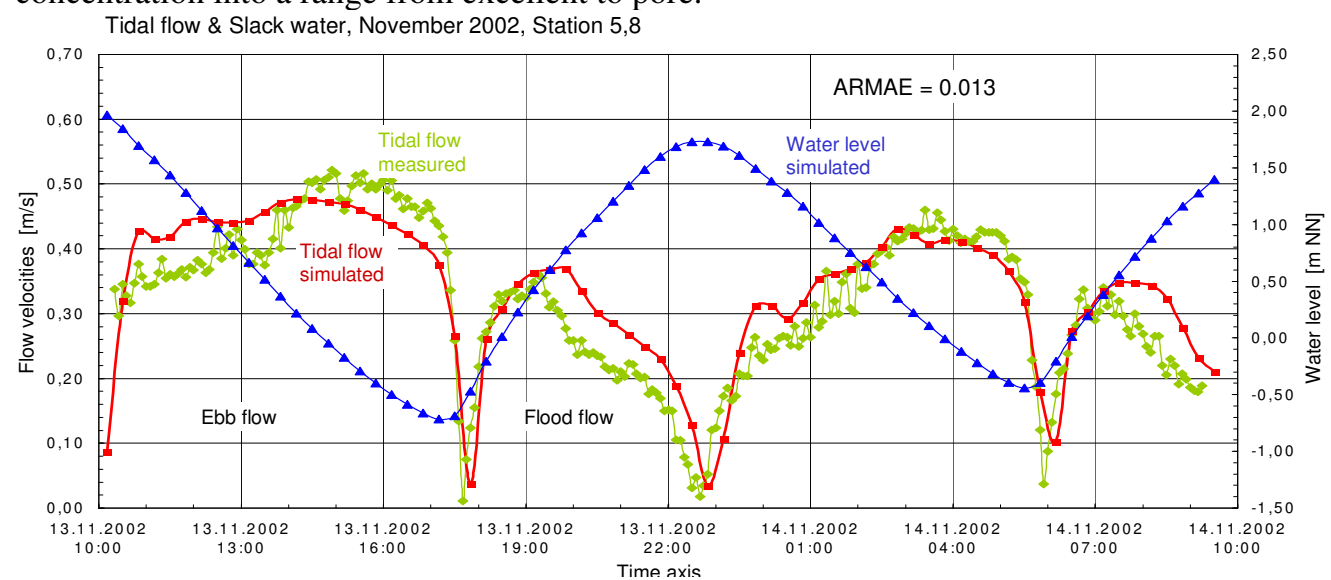

Suspended sediment concentration in the tidal zone, Mai 2008

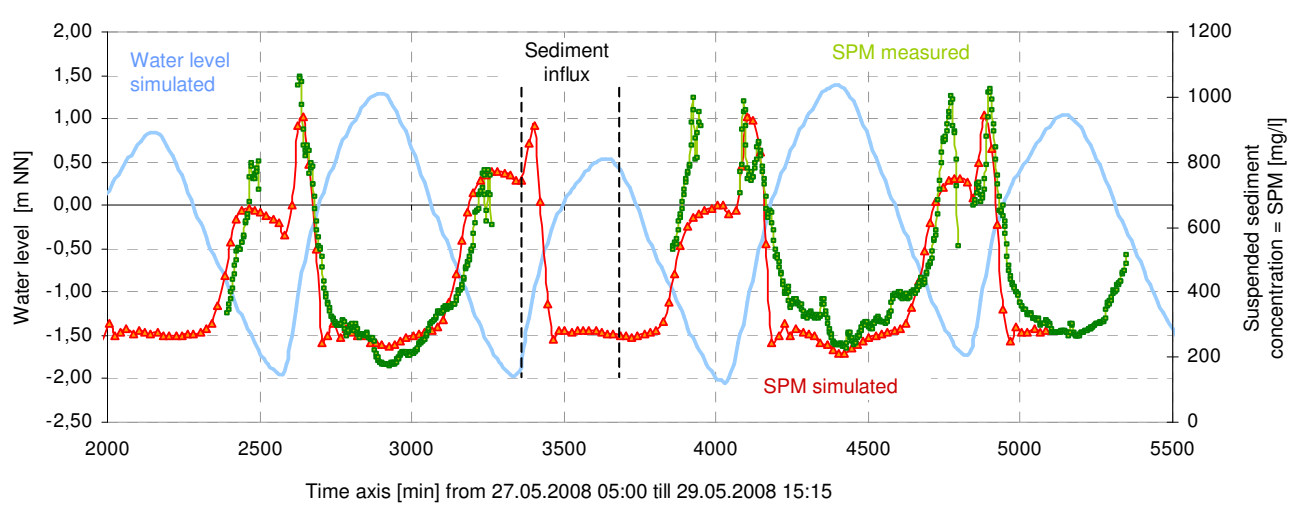

Figure 10: Measured and simulated tidal flow from November 2002 near Station 5,8 (top), measured and simulated suspended sediment concentration in the tidal zone near the mouth from Mai 2008 (bottom)

For the calibration of hydrodynamics an HQ-event (22.02 - 03.03.2000) with $11.3 \mathrm{~m}^{3} / \mathrm{s}$ runoff and a tidal range of $3.4 \mathrm{~m}$ and an NQ-event (26.04 - 27.04.2000) with $0.7 \mathrm{~m}^{3} / \mathrm{s}$ runoff and a tidal range of $2.7 \mathrm{~m}$ were selected. For roughness parameters a ks-value of 0.5 to $1.2 \mathrm{~cm}$ in the tidal zone, 1.5 to $15 \mathrm{~cm}$ in the backwater and runoff-zone were adopted. For turbulence a vertical mixing coefficient $\varepsilon_{\mathrm{z}}$ of 0.135 and a Smagorinsky coefficient $\mathrm{c}_{\mathrm{s}}$ of 0.18 subject to the term of minimal eddy viscosity of 0.01 to $0.15 \mathrm{~m}^{2} / \mathrm{s}$. For both calibration events the ARMAE for water level was excellent in the tidal zone with less than 0.05 and good with less than 0.3 in the backwater zone. For the flow velocities an excellent range as achieved with an ARMAE less than 0.06. Three additional validation scenarios from Nov 2001, Nov 2002, Nov 2006 with discharges of 2.1 to $2.7 \mathrm{~m} 3 / \mathrm{s}$ and a tidal range of 2.6 to $3.3 \mathrm{~m}$ represented also an excellent range for water level and flow velocities based on the ARMAE (Figure 10 , top).

For the calibration of sediment transport processes, at first the SPM influx near the upper boundary below the mouth of the river Offenau is analysed. In deviation from the hydrodynamics the regression functions are taken into account in order to examine sediment transport behaviour over the full discharge range $\left(0.2\right.$ to $\left.11.5 \mathrm{~m}^{3} / \mathrm{s}\right)$. In a second calibration step the sediment influx at the lower boundary based on the hysteretic functions is also included and compared to measured SPM-time series (Figure 10, bottom). At the tidal boundary the influx of SPM concentrations varies between 15 and 5\% 
and the outflux SPM concentrations between 30 and 10\%. The ratio between maximum SPM out- to influx is $1: 1$ to $1: 1.6$ for measured and $1: 1.1$ to $1: 1.4$ for simulated values. In the backwater zone the SPM concentrations differs between -7 to $+9 \%$ over the full discharge range (mean deviation $0.8 \%$ ). Sediment parameters like settling velocities, which are based on measured values are not modified anymore, due to calibration. Empirical parameters like bulk density, critical shear stress and erodibility factor are slightly modified in the set-up range (see above). As results the dry bulk density varies between 1100 to $1500 \mathrm{~kg} / \mathrm{m}^{3}$ for suspended layers and 1450 to $1960 \mathrm{~kg} / \mathrm{m}^{3}$ for bed layers. Critical shear stress varies between 0.13 to $0.66 \mathrm{~N} / \mathrm{m}^{2}$ for suspended layers and 0.42 to $3.0 \mathrm{~N} / \mathrm{m}^{2}$ for bed layers. The erodibility factor varies between 0.01 to $0.14 \mathrm{~g} / \mathrm{m}^{2} / \mathrm{s}$ for suspended layers and 0.02 to $0.28 \mathrm{~g} / \mathrm{m}^{2} / \mathrm{s}$ for bed layers. The critical shear stress for deposition according to Krone (1962) lies in the range of 0.01 to $0.12 \mathrm{~N} / \mathrm{m}^{2}$ in the backwater zone and between 0.05 to $0.10 \mathrm{~N} / \mathrm{m}^{2}$ in the tidal zone.

\section{Validation of long-term approach}

On macro-scale morphodynamic bed evolution with the multi-layer soil model are focused on. The validation of the developed long-term approach is carried out in three steps by a comparison of final bed evolution for different approaches, morphological factors and boundary conditions. All three steps start from the same initial conditions with the bed level of 2006, with one tidal and two discharge boundaries including sediment influx. For evaluation of the results five statistic key values are applied: the covariance R, mean error ME, mean square error MSE, Brier Score BS, and Brier Skill Score BSS according to Casati et al. (2007):

$$
B S S=1-\frac{1}{n} \cdot \frac{\sum_{i=1}^{n}\left(Y_{i}(t)-X_{i}(t)\right)^{2}}{\sum_{i=1}^{n}\left(\overline{X(t)}-X_{i}(t)\right)^{2}}, \text { with BSS }=1: \text { perfect }
$$

where $\mathrm{n}$ is the number of points, $\mathrm{X}_{\mathrm{i}}(\mathrm{t})$ measured or reference values, $\mathrm{Y}_{\mathrm{i}}(\mathrm{t})$ simulated or scenario values and $\overline{X(t)}$ mean value or initial condition with $X_{i}\left(\mathrm{t}_{0}\right)$ (Zanke, 2008).

A first validation-step (A) analyses, how fare an acceleration of simulation is feasible by using different morphological factors for NQ up to HQ-events. Therefore 7 tides (tidal range $3.1 \mathrm{~m}$ ) interact with a flood wave (discharge range 1.3 to $11.5 \mathrm{~m} / \mathrm{s}$ ) over a time span of $22 \mathrm{~d}$, due to recurrence and/ or morphological factors. This HQ event is simulated with MF 1 and 6 reruns, MF 3 and 2 reruns and MF 6 and 1 rerun (Figure 11). A similar study is achieved over 8 tides (tidal range $3.1 \mathrm{~m}$ ), which interact with a NQ to MQ events (discharge range 0.2 to $1.5 \mathrm{~m} / \mathrm{s}$ ) over a time span of $99 \mathrm{~d}$, due to recurrence and/ or morphological factors. This NQ-MQ event is simulated with MF 6 and 4 reruns, MF 12 and 2 reruns and MF 24 and 1 rerun.

Bed evolution over time in the tidal and backwater zone for different morphological factors (MF) and reruns
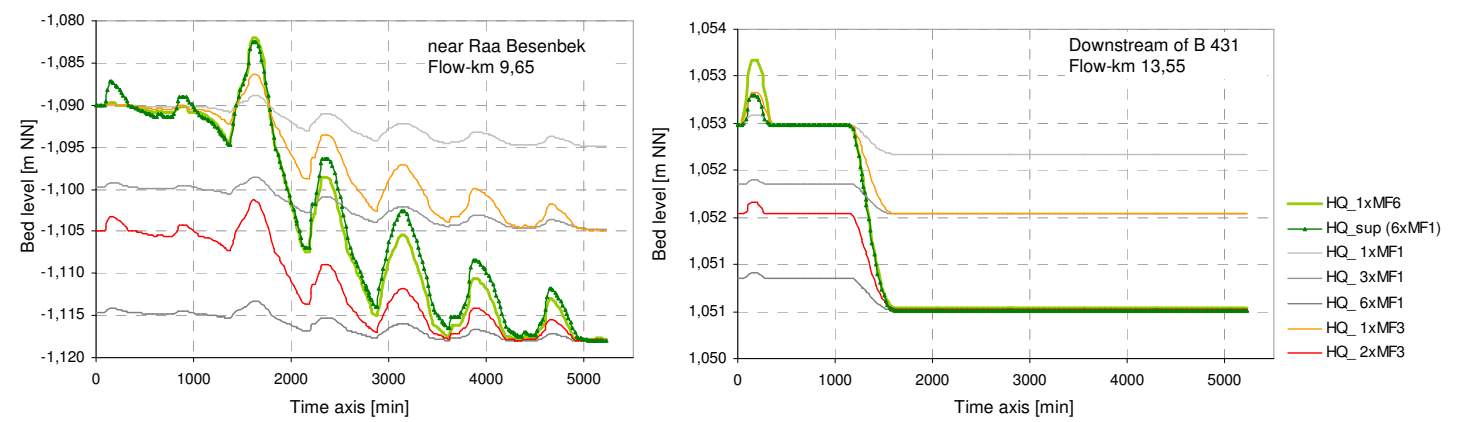

Figure 11: Bed evolution over time in the tidal and backwater zone for different morphological factors (MF) and reruns for the HQ-event, validation-step (A)

Both events and all modifications result in $\mathrm{R} \leq 0.99$ and $\mathrm{BSS} \leq 0.98$. The mean error ME was smaller than $\pm 1.2 \mathrm{~cm} / \mathrm{a}, \mathrm{MSE} \leq 14.9 \mathrm{~cm} / \mathrm{a}$ and $\mathrm{BS} \leq 12.3 \mathrm{~cm}^{2} / \mathrm{a}$. Even though all morphological factors achieved good statistic values, a detailed look on the comparison showed some shortcomings. For HQevents especially erosion in the backwater and runoff zone is over estimated by MF over 3 or 4, while bed evolution in the tidal zone is well performed with all factors from 1 to 6 . For NQ-MQ-events the bed evolution in runoff zone is well performed with all factors, but at the riverbanks of the backwater and tidal zone deposition is slightly overestimated for MF over 12. As consequence MF should be 
limited to MF 4 for flood events and to MF 12 for mean or low discharges. For these factors mean error ME was smaller than $\pm 0.7 \mathrm{~cm} / \mathrm{a}, \mathrm{MSE} \leq 6.5 \mathrm{~cm} / \mathrm{a}$ and $\mathrm{BS} \leq 2.5 \mathrm{~cm}^{2} / \mathrm{a}$.

A second validation-step (B) analyses the question, whether the synthetic discharge hydrograph including morphological factors as developed in (A) cope with a comparable, natural discharge hydrograph based on the duration curve. Therefore the real discharge hydrograph of 2000 was simulated without an acceleration of simulation over 1 year combined with synthetic neap-spring tides and barrier management at the tidal boundary. The synthetic discharge hydrograph, which consists of 3 basic scenarios (range 0.2 to $9.5 \mathrm{~m}^{3} / \mathrm{s}$ ) with the neap-spring tides at the tidal boundary (Table 1) were applied and accelerated by MF 1.2 to 5.9. The comparison of final bed evolution results a mean delta of $+0.6 \mathrm{~cm} / \mathrm{a}$ or $7.4 \%$. The highest depositions appear in small bays and sidewise harbours, while the highest erosion occur in the runoff-zone, due to bank erosion during floods. The maximum deltas at the riverbed are in the range of $\pm 5 \mathrm{~cm}$. The comparison results in $\mathrm{R}=0.98$ and $\mathrm{BSS}=0.96$. The mean error $\mathrm{ME}$ was $\pm 0.6 \mathrm{~cm} / \mathrm{a}, \mathrm{MSE}=5.2 \mathrm{~cm} / \mathrm{a}$ and $\mathrm{BS}=27.4 \mathrm{~cm}^{2} / \mathrm{a}$. These deviations are almost similar to the statistic key values from (A), so only a small error can be assumed for the application of synthetic discharge hydrographs in combination with morphological factors.

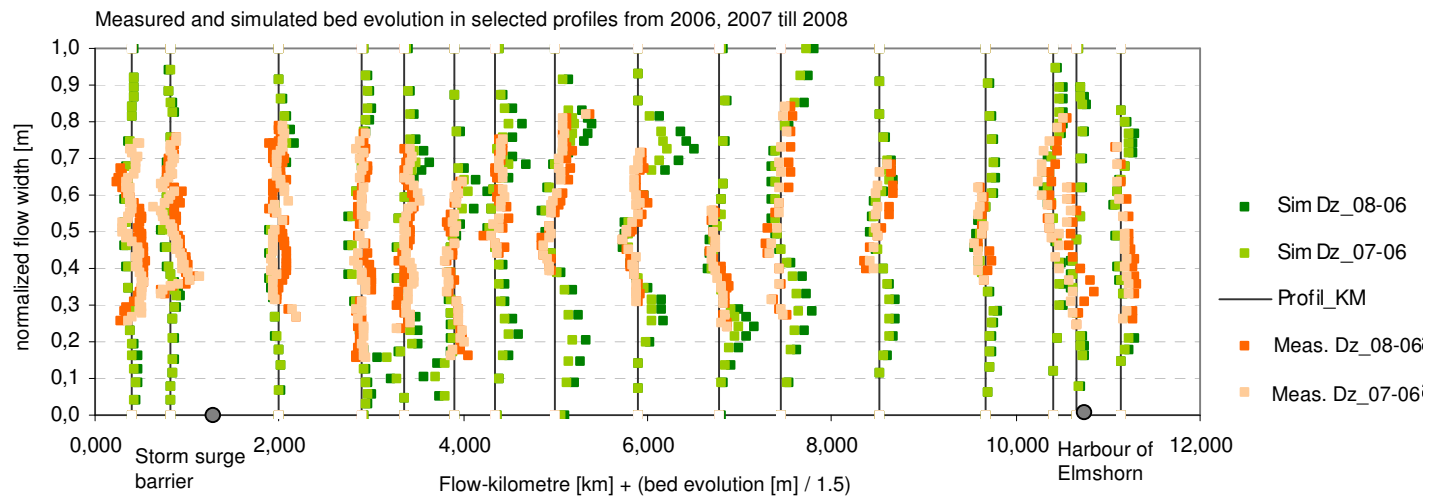

Figure 12: Measured and simulated bed evolution in selected profiles from 2006 till 2008, validation-step (C)

The final validation (C) includes all findings from (A) and (B). Applying all synthetic hydrographs combined with the respective morphological factor (Table 1) bed evolution from 2006 till 2009 is simulated and compared to measured bed evolution. Due to this combination, (C) gives the final and overall uncertainty of the long-term approach. At first the hydrological years 2006 to 2009 are assigned to synthetic hydrographs, based on the natural range and characteristics. For 2007 the discharge range is 0.2 to $9.5 \mathrm{~m}^{3} / \mathrm{s}$ (HQ2) with MF from 1.1 to 5.9 . For 2008 the discharge range is 0.2 to $11.5 \mathrm{~m}^{3} / \mathrm{s}$ (HQ5) with MF from 1.3 to 5.0 and for 2009 the discharge range is 0.2 to $7.6 \mathrm{~m}^{3} / \mathrm{s}$ (HQ1) with MF from 1.0 to 6.8. The characteristics of bed evolution are represented by the long-term approach (Figure 12): In the middle reach of the tidal zone riverbed is slightly eroded, while the banks are deposited. In the backwater of the storm surge barrier the riverbed trends slightly to deposition. Also at the end of the tidal zone near the harbour of Elmshorn depositions at the riverbed and at the banks occur. The comparison between measured and simulated bed evolution by statistic value results in quite good to adequate ranges with a mean error of $-1.6 \mathrm{~cm} / \mathrm{a}$ for 2006 till 2007 (BSS 0.91), $-1.4 \mathrm{~cm} / 2$ a for 2006 till 2008 (BSS 0.91) and +0.03 cm/3a for 2006 till 2009 (BSS 0.68).

\section{RESULTS AND DISCUSSION}

\section{Advantages and Limitations of the long-term approach}

The validation for feasible morphological factors was examined for different conditions from low to flood discharge events in interaction with tides and results in morphological factors of 4 for HQevents up to 12 for low to mean discharge. As consequence an acceleration of simulation by applying MF in a sensitive way is also possible for tidal marsh-watercourses, under consideration of some limits. These factors are not only able to reduce the simulation time, but also provide the opportunity to compensate the time span differences between neap-spring tides and hydrological years. Also the application of synthetic hydrographs at the inflow and tidal boundaries give good results compared to bed evolution of a real hydrograph without acceleration. The developed long-term approach is able to represent the characteristics of bed evolution from 2006 to 2009 with an adequate quality. Different sensitivity analysis gains more insight into inherent uncertainties in this approach. Therefore the scatter range of SPM-influx and the impact of barrier management on sediment dynamics are focused on. 
Impact of storm surge barrier management

The barrier management is included into the long-term approach and represents some slight trends and behaviour characteristics in time series of bed evolution. The oscillating water level of the synthetic neap-spring-tides (Figure 13, top) induces also a periodic oscillating bed evolution in the main channel of the tidal zone. During spring tides a slight trend of erosion appears, while neap tides evoke a trend of deposition. Due to both barrier management strategies, suspended sediments settle and a short time-span of deposition occur, but under tidal velocities sediments are remobilised soon after (Figure 13, bottom). These characteristics in the main channel change at the riverbanks and in shallow water sections, where a sustainable deposition appears during barrier closure. These aggradations are not remobilised under tidal velocities.
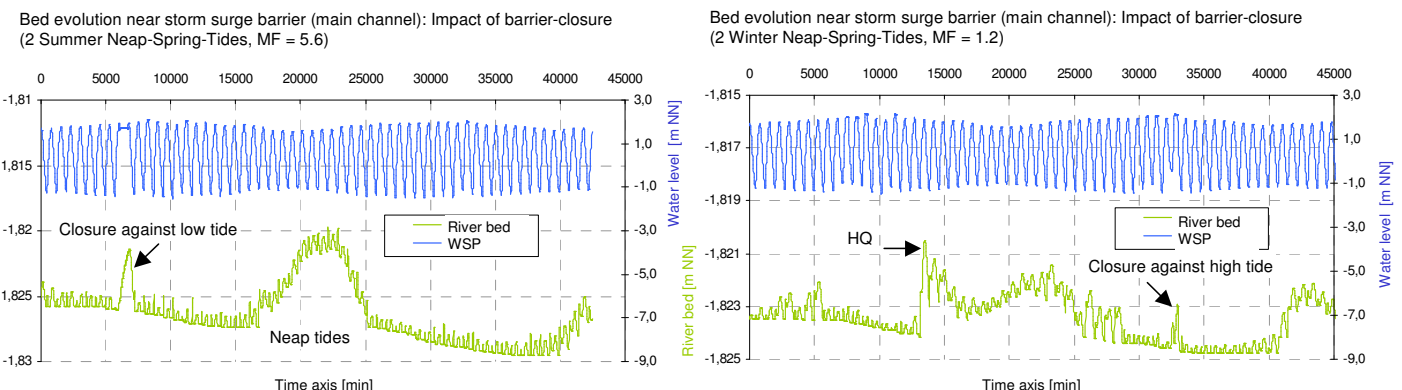

Figure 13: Bed evolution in the backwater of the storm surge barrier (main channel) with impact of barrierclosure during summer neap-spring-tides (left) and winter neap-spring-tides (right)

In order to examine the impact of barrier management additional scenarios with sequenced closed and open tidal boundary apart from the synthetic hydrographs were analysed. Therefore constant inland runoffs with NQ $\left(0.6 \mathrm{~m}^{3} / \mathrm{s}\right)$, MQ $\left(1.3 \mathrm{~m}^{3} / \mathrm{s}\right)$ and HQ $\left(9.5 \mathrm{~m}^{3} / \mathrm{s}\right)$ were combined with an open tidal boundary over 7 tides, a sequenced closure against high and low tide. The results of these nine scenarios were analysed within their (tidal residual) net sediment flux, width integrated net sediment flux and position of turbidity maximum. The turbidity maximum with ca. $600 \mathrm{mg} / \mathrm{l}$ is near flow-km 6.0 for NQ. Due to barrier management, this turbidity maximum remains in the same position and only for closure against low tide the intensity is reduced to $300 \mathrm{mg} / \mathrm{l}$. For an HQ the turbidity maximum with ca. $900 \mathrm{mg} / \mathrm{l}$ moves downstream to flow-km 4.5. The position and intensity of turbidity maximum remains for closure against high tides. For closure against low tide the tidal induced turbidity maximum disappears.

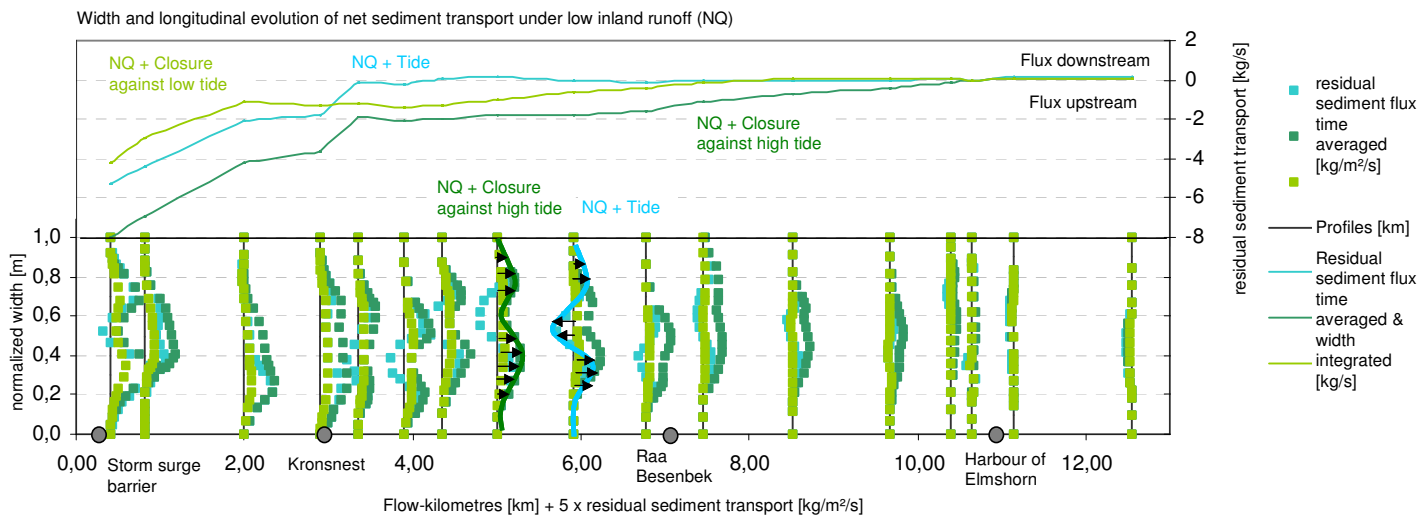

Figure 14: Width and longitudinal evolution of net sediment transport under low discharge (NQ) and different tidal conditions with residual sediment flux (bottom) and with width-integrated sediment flux (top)

For NQ and an open tidal boundary the net sediment flux points upstream in shallow water sections, but points downstream in deep water, like the main channel (Figure 14, bottom). Both barrier closures under NQ amplify a net sediment flux upstream, which is distinct for closure against high tides and smaller for closure against low tide. For both conditions the cross-sectional variation is suppressed. For NQ with an open tidal boundary also a width-integrated net sediment flux upstream occurs, which ends after about $3 \mathrm{~km}$ (Figure 14, top). For both barrier closures this upstream transport extends up to $7 \mathrm{~km}$ and $11 \mathrm{~km}$. For all tidal boundary conditions combined with low discharge ,tidal pumping“" occurs and is amplified by barrier management. During flood events net sediment flux points downstream and is only slightly reduced due to barrier management. 
4

\section{Impact of suspended sediment influx}

The sensitivities of SPM influx at the tidal and inflow boundaries is analysed by using a scatter range of the regression functions based on field measurements. These field measurements represent a scatter range of $\pm 100 \mathrm{mg} / \mathrm{l}$ to mean value of SPM at the inflow boundaries and $\pm 150 \mathrm{mg} / \mathrm{l}$ at the tidal boundary. The effect of lower or higher SPM influx is examined in four scenarios under equal hydraulic conditions by using the MQ-MHQ event (Table 1) with MF 2.4. The final bed evolution after 142 days represented a high sensitivity due to variable SPM-influx at the tidal boundary $( \pm 150 \mathrm{mg} / \mathrm{l})$. For a higher tidal SPM-influx the mean variance is $+3.9 \mathrm{~cm} / \mathrm{a}(+30 \%$, BSS 0.78$)$ and for lower tidal SPM-influx the mean variance is $-2.8 \mathrm{~cm} / \mathrm{a}(-25 \%$, BSS 0.86). The modified tidal SPM-influx implicates an impact in the tidal zone from the mouth to about $6 \mathrm{~km}$ into the backwater. But changes for bed evolution only appear at the banks, in tidal creeks and in shallow water zones, where deposition is reduced for lower tidal SPM-influx and increases for higher tidal SPM-influx (Figure 15).

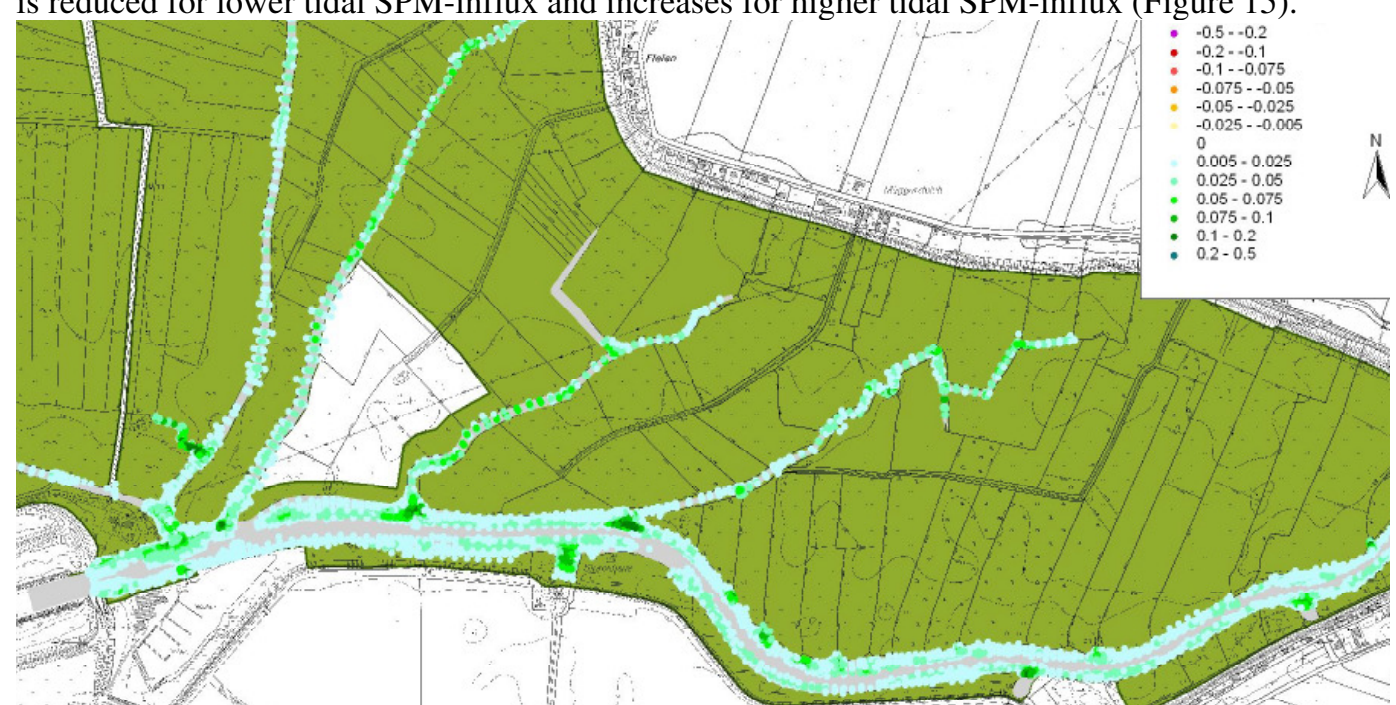

Figure 15: Delta of bed evolution and its sensitivity due to higher SPM-influx at the tidal boundary $+150 \mathrm{mg} / \mathrm{l}$ in $[\mathrm{m} / 4$ month]

Compared to the impact of tidal influx, the variability of SPM-influx at discharge boundaries $( \pm 100 \mathrm{mg} / \mathrm{l})$ represents a mean sensitivity. For a higher discharge SPM-influx the mean variance is $+1.2 \mathrm{~cm} / \mathrm{a}(+9 \%$, BSS 0.96) and for lower discharge SPM-influx the mean variance is $-1.0 \mathrm{~cm} / \mathrm{a}(-9 \%$, BSS 0.98). The modified discharge SPM-influx implicates an impact in the backwater and the upper part of the tidal zone. And changes for bed evolution not only appear at the banks and in shallow water zones, but also in the main channel.

\section{CONCLUSIONS AND OUTLOOK}

The presented long-term approach for tidal marsh-watercourses with cohesive sediments by suing synthetic hydrographs for tide and inland runoff, combined with regression functions for SPM-influx, shows good consistence compared to bed evolution based on field measurements. In compliance with certain limitations an acceleration of simulation by morphological factors can be achieved including anthropogenic impacts like the operation of a storm surge barrier. The barrier management deforms dynamics of sediment transport and is able to enforce tidal pumping. A long lasting impact of deposition appears especially in shallow water zones and at the riverbanks. But also deposition in the main channel near the barrier was measured. The tidal SPM-influx shapes the banks and forces deposition in shallow water regions, while hydraulic forces deform deepwater channels. Different sensitivity analysis gain more insight into inherent uncertainties in this approach and will be integrated into the uncertainty of the riverbed evolution over the next 20 years. By using this long-term approach further sediment strategies, like sediment retention or modified barrier management can be analysed as a further objective.

\section{ACKNOWLEDGEMENT}

The authors thank the Municipal Water Treatment and the Municipal Administration of Elmshorn for enabling the related R\&D project, as well as the authorities WSA-Hamburg, LKN Itzehoe and LLUR. 


\section{REFERENCES}

Casati, B., Wilson, L. J. 2007. A New Spatial-Scale Decomposition of the Brier Score: Application to the Verification of Lightning Probability Forecasts, Meteorological Research Division, Environment Canada, Monthly Weather Review 135, Dorval, Quebec, pp. 3052-3069.

De Vriend, H. J., Zyserman, J., Nicholson, J., Roelvink, J. A., Pechon, P., Southgate, H. N. 1993. Medium-term 2DH coastal area modelling, Coastal Engineering, Vol. 21, pp.193-224, Amsterdam.

De Vriend, H. J. 2001. Long-Term morphodynamic prediction, in Coastal and Estuarine Morphodynamics, Springer-Verlag Berlin Heidelberg, pp. 163-190.

Donner, M., Pasche, E., Nehlsen, E. 2009. Impact of storm surge barriers on morphodynamic processes in tidal lowland-rivers, Conference Proceedings IAHR, Vancouver, Canada.

Doyle, M. W., Shields, D., Boyd, K. F., Skidmore, P. B., Dominick, D. 2007. Channel-Forming discharge selection in river restoration design, Journal of Hydraulic Engineering, Vol. 133, No. 7.

Dronkers, J. 1986. Tidal Asymmetry and Estuarine Morphology, Netherlands Journal of Sea Research, No. 20 (2/3), pp.117-131.

Dronkers, J., Van Leussen, W. 1988. Physical processes in Estuaries, Springer Verlag Berlin Heidberg.

EC 2006/60. 2000. Water Framework Directive for Community Action in the field of water policy, Official Journal of the European Communities, L327/1, Brussels.

EC 2007/60. 2007. Directive of European Parliament and of the Council on the assessment and management of flood risks, Brussels.

Greenberg, R., Maldonada, J. 2004. Diversity and endemism in tidal-marsh vertebrates, Studies in Avian Biology, No. 32, pp. 32 - 37.

Junge, I., Wikens, J., Hoyme, H., Mayerle, R. 2005. Modelling of Medium-Scale Morphodynamics in a Tidal Flat Area in the South-Eastern German Bight, Die Küste, No. 69, pp. 277-310.

Latteux, B. 1995. Techniques for Long-Term morphological simulation under tidal action, Marine Geology, Volume 126; pp.129-141.

Rubbert, S. 2007. Entwicklung eines Langfristgewässergütemodells für flache Standgewässer, Dissertation, Institut für Wasserbau und Wasserwirtschaft, RWTH Aachen.

Salomon, J. C., Allen, G. P. 1983. Role sedimentologique de la mare dans les estuaires a fort marnage, Compagnie Français de Petroles, Notes and Memoires 18, pp. 35-44.

Schonlau, H. U. 2007. Zeitskalenübergreifende Berücksichtigung von partikulärem Stofftransport in einer Langfrist-Gewässergüteprognose für Fließgewässer, Dissertation, Fakultät für Bauingenieurwesen, RWTH Aachen.

Schrage, N., Antanaskovic, D., Jung, T., Pasche, E. 2009. KALYPSO - An open source software tool for flood studies in rivers, Conference Proceedings International Conference on Hydroinformatics, Concepción, Chile.

Schweim, C. 2005. Modellierung und Prognose der Erosion feiner Sedimente, Dissertation, Fakultät für Bauingenieurwesen, RWTH Aachen.

Steijn, R. C. 1992. Input Filtering Techniques for Complex Morphological Models, Delft Hydraulics Report, H 824.53.

Temmerman, S., Gover, G., Wartel, S., Meire, P. 2004. Modelling estuarine variations in tidal marsh sedimentation, Marine Geology, No 212, Elsevier, Amsterdam.

Van Rijn, L. C. 1993. Principles of sediment transport in rivers, estuaries and coastal seas, Aqua Publications, Amsterdam, pp. 11.9 - 11.14.

Van Rijn, L. C., Grasmeijer, B., Sutherland, J., Pan, S., Sierra, J. P., Van Rijn, B., Ruessink, B. G., Mulder, J. P. 2002. Simulation of nearshore hydrodynamics and morphodynamics on the tidal scale of storms and seasons using process-based profile models, COAST3d-EGMOND, Aqua Publications, Amsterdam, pp. 213-233.

Zanke, U. C. 1982. Grundlagen der Sedimentbewegung, Springer Verlag, Berlin Heidelberg.

Zanke, U. C., Hirschhäuser, T. 2001. Morphologische Langfristprognose für das System TidebeckenAußensände am Beispiel Sylts und der Dithmarscher Bucht, Die Küste, No. 64, pp.127-160.

Zanke, U. C., Hirschhäuser, T. 2004. Langfristige Sedimentdynamik des Systems Tidebecken-Ebbdelta unter besonderer Berücksichtigung von verändertem Seegang und Wasserständen, Die Küste, No. 68, pp.201-248.

Zanke, U. C. 2008. On applicability of morphodynamic acceleration in morphodynamic simulations, Mitteilungen des Instituts für Wasserbau und Wasserwirtschaft der TU Darmstadt, Heft 144. 